\title{
FRANCISCO GINER DE LOS RÍOS O EL ARTE DE FORJAR ALMAS
}

\author{
José Luis GonZÁlez Geraldo \& Benito del Rincón IgEA \\ Universidad de Castilla-La Mancha
}

\section{Resumen}

Este trabajo tiene por objeto dibujar el perfil educador de Francisco Giner de los Ríos, el hombre más carismático de la Institución Libre de Enseñanza. Apoyándonos sobre todo en el testimonio escrito de algunos de sus discípulos más cualificados, estas páginas reflejan la actividad de un maestro universitario a pie de obra. Giner superó el horizonte de su época porque se opuso al memorismo estéril y construía el saber con sus discípulos, planteando problemas e invitando a encontrar soluciones. Era, en definitiva, un educador moderno, de corte europeo. Y lo era allá donde estuviera; por eso, con su buen hacer pero, sobre todo, con su ser, iluminó una herencia pedagógica de cuatro décadas, ya en el siglo XX. Que a los educadores de hoy, bien entrado el XXI, nos sirva para reforzar nuestra responsabilidad y redoblar esfuerzos en la tarea, seguramente, más comprometida que existe.

Palabras clave: Francisco Giner de los Ríos; Institución Libre de Enseñanza; ILE; educación; krausismo.

\begin{abstract}
The aim of these lines is to present the portrait of the most charismatic educator of the Institución Libre de Enseñanza: Francisco Giner de los Ríos. Building our discourse on the written testimony of some of his most qualified disciples, these pages show the activity of a university teacher - not just a professor-. Giner exceeded the horizon of his time because he opposed the sterile memorization and built knowledge with his disciples, not only proposing problems but also inviting them to solve them. In short, he was a modern educator who was aware of the European way of teaching. And he was all these things regardless of the place where he was. Therefore, with his savoir faire, but above all thanks to his great way of being, he lit a pedagogical legacy of four decades within the twentieth century. His life may be a good mirror in which educators could see their duties and efforts reflected.
\end{abstract}

Keywords: Giner de los Ríos; Institución Libre de Enseñanza; ILE; education; krausism.

Anales, 27 (2015), pp. 179-200

DOI: 10.14198/ALEUA.2015.27.10 


\section{Introducción}

Se piensa comúnmente de él que consagró toda su vida a la educación. Y es verdad. Más verdad de lo que comúnmente se piensa.

L. ZULUETA

Pocas semanas después de la muerte de Francisco Giner de los Ríos, el 18 de febrero de 1915, el historiador Rafael Altamira publicó un libro homenaje con un sugerente y significativo título: Giner de los Ríos. Educador. La elección del calificativo no fue baladí. Él mismo profundiza en sus páginas para justificar esta elección:

He procurado evitar la palabra «pedagogo» al hablar de Giner. No es que la crea impropia tratándose de lo que él fue principalmente, sino que se ha abusado tanto de ella entre nosotros y se la ha aplicado a tantas cosas solo en la apariencia equivalentes, que he temido un equívoco. Si llamamos «pedagogo» al que sabe de Pedagogía (es decir, doctrina de los demás, y aun al que la elabora propia), es lícito que reservemos la palabra «educador» para quien, independientemente de lo que sepa e invente de esa disciplina, eduque. Puede un hombre poseer toda la ciencia pedagógica posible y ser, por las condiciones fundamentales de su espíritu, incapaz de educar. Todas las recetas juntas de todos los pedagogos, no conseguirán que sea «maestro» un sabio de alma zafia, egoísta, falta de dulzura y ductilidad (Altamira, 1915b: 72-73).

De esta forma quiso recordar Altamira al que fue cabeza visible de uno de los movimientos de ruptura y cambio pedagógico de mayor éxito y calado en nuestro país: la Institución Libre de Enseñanza (ILE). La huella de Giner no solo quedó grabada en las páginas de su legado bibliográfico, sino también, y quizá sobre todo, en los corazones de aquellos que tuvieron la suerte de comprobar el entusiasmo, la sencillez y la amplitud de espíritu del maestro de maestros, apóstol de la enseñanza, pescador de hombres, santo laico, conductor de almas, san Francisco Giner, don Paco Giner, el abuelito o, simplemente, don Francisco. De hecho, todavía hoy sigue vigente el debate que él, quizá por primera vez en España (García Velasco, 2011), entabló entre una labor pedagógica educativa y otra meramente instructiva.

Cien años han pasado desde que nos abandonó y es deseable, pero también necesario, rendir justo homenaje a su figura tal y como en su momento se hizo en el cincuentenario de su querida ILE (Giner de los Ríos, 1926), en el cincuentenario de su muerte (Giner de los Ríos, 1965) 
y, de nuevo, en el centenario de la primera (Programa de la Institución Libre de Enseñanza, 1976). Con este objetivo en mente, estas líneas profundizarán en su obra desde una perspectiva que normalmente suele escapar a los trabajos que tienen en consideración sus libros, ensayos, artículos y demás escritos que resaltan el compromiso pedagógico y la talla intelectual de Francisco Giner de los Ríos. Los textos de Giner son dignos de estudio, pero no obstante «con ser estimabilísimos [...], no darán a la posteridad idea cabal del inmenso valor de este hombre, superior a sus obras escritas» («Estudiante y maestro», 1915: 1). Cossío, discípulo predilecto de Giner, solía excusarse cuando alguno de sus estudiantes le pedía que escribiera algo sobre lo que acababa de enseñarles, pues no veía necesidad en repetir lo que había sido vivido, algo que sin duda aprendió de don Francisco, pues «[e]s manifiesto el desdén de estos hombres por trasladar a obras acabadas su inquietud docente. Se esforzaban sobre todo en ofrecer ellos mismos un modelo de vida; ellos mismos "se escribían" en el comportamiento de sus alumnos» (Molero, 2000: 78).

Cuando alguien pregunta a un profesor a qué se dedica, este rápidamente suele acotar el rango de su influencia a la asignatura impartida. Así, solemos encontrarnos con profesores de historia, de música, de física, etc. Pocos caemos en lo obvio: ante todo somos profesores de seres humanos. El arte de hacer hombres, haciendo patente lo que en ellos es latente (López-Morillas, 1989), forjando personas y no solo profesionales, era sin duda la obra lenta, pero segura, que quisieron Giner y sus colaboradores. De ahí que el calificativo de pedagogo, pese a ser pertinente, le quede pequeño al compararlo con el de educador.

Por estos motivos, consideramos necesario realizar un viaje al epicentro de su día a día, penetrando en aquellas clases donde la relación entre maestro y discípulo era total (Molero, 1987), convirtiendo la enseñanza en un desdibujado ente abstracto difícil de encajar en las premisas de nuestro siglo. Un siglo demasiado preocupado por la posada y no tanto por el camino - por los resultados y no tanto por los procesos-, pero donde todavía puede encontrar su reflejo, más o menos borroso pero igualmente pertinente y deseable (González Geraldo, 2011).

Para conseguirlo hemos acudido al recuerdo de las personas que de él recibieron influencia, bien fuera en relación con su cátedra o en la ILE, y que días, meses e incluso años más tarde, plasmaron por escrito sus vivencias para honrar su memoria y agradecer la educación recibida. Por tanto, no es la voz de Giner la que paladearemos, sino la de sus discípulos; no acudiremos a la semilla, sino a los frutos. Este tipo de escritos solían 
producirse con más frecuencia de la que quizá creamos, sobre todo desde febrero de 1915 y casi siempre en el aniversario de su muerte. Muchos de estos artículos y recuerdos fueron compilados en la sección In Memoriam del BILE ${ }^{1}$. En el fondo «Giner» de la Real Academia de la Historia (34-680/41-763/41-770) están custodiados muchos de los recortes de periódico, e incluso algunos manuscritos originales, de los elogios que posteriormente serían publicados en el BILE. La naturaleza de los artículos recogidos en esta sección del boletín no es solo numerosa sino también ecléctica; por ello hemos priorizado aquellos que no solo exponen aspectos que son de utilidad a la hora de reconstruir la docencia de don Francisco, sino también aquellos que fueron narrados en primera persona, como si de una confesión al diario personal se tratara, admitiendo con ello el beneplácito del giro hacia el individuo que deriva de una concepción posmoderna de la investigación historiográfica, en nuestro caso, educativa. No es casualidad, por tanto, que al igual que en la obra que se publicó en el cincuentenario de su muerte (Giner de los Ríos, 1965), muchas de las referencias utilizadas procedan del BILE.

Este trabajo está estructurado en cuatro partes: su vida, su institución, su cátedra y su huella. Nos ayudará a evocar el momento de aquellas clases y también los sentimientos que en ellas se fraguaron, así como el cúmulo de circunstancias que hicieron de don Francisco una fuente inagotable de influencia educativa.

\section{Su vida}

Como ocurre con muchos de los mejores españoles, la personalidad de D. Francisco ha sido muy superior a su obra escrita. La posteridad no podrá comprender el influjo decisivo ejercido por el maestro sobre sus contemporáneos.

A. REYES

En la vida de Giner podemos diferenciar tres momentos: su etapa como estudiante, sus primeros años como catedrático y finalmente su cenit como fundador de la ILE (Molero, 2000: 34). Seguiremos los dos primeros puntos para conocer, breve pero necesariamente, a la persona que dio lugar al educador y establecer las bases que nos permitirán bosquejar los

1. En 1929 dejan de publicar la sección In Memoriam. Vuelve a aparecer, de manera esporádica, a partir de marzo de 1930 hasta finales de 1936. Hay que resaltar cómo la muerte de Cossío en 1935, entre otros, recoge el testigo de recuerdos que hasta entonces había ocupado, principalmente, la figura de Giner. 
fundamentos de la ILE, institución sin la cual sería imposible entender el calado de la obra de Giner.

Francisco Giner de los Ríos fue el mayor de seis hermanos. Nació en una casa de tres plantas en la ciudad Ronda el 10 de octubre de 1839, teniendo la fortuna de ser criado por una madre inquieta, inteligente y con una cultura que sobrepasaba lo que, para su época, podría esperarse. Su padre fue funcionario de Hacienda, posibilitando una vida acomodada, pero también sujeta a traslados frecuentes, que hicieron que sus años de estudiante discurrieran en distintas ciudades: enseñanza primaria en Cádiz y bachillerato en Alicante.

Giner gozó de una «expresión inteligente y delicada, con gran viveza en el mirar, un rasgo que le caracterizó siempre» (Jiménez-Landi, 1996a: 84), tal y como puede comprobarse en cada retrato y fotografía, donde unos ojos oscuros, casi siempre en una ladeada cara con claras reminiscencias árabes, nos invitan a creer en la serenidad estoica y la pasión ardiente, romántica y aristocrática que le caracterizaba (Castillejo, 1937). Tanto su familia como sus maestros pronto se rendirían ante la sagacidad del joven Giner. Tal y como apuntó su abuelo, «[e]ste niño me admira por sus preguntas y por sus respuestas. O mucho me equivoco, o dará que hablar» (en Jiménez-Landi, 1996a: 83).

En Barcelona se inicia en el derecho y la filosofía de la mano de F. Javier Llorens y Barba, de quien aprendió el amor por la profesión docente más que las doctrinas recibidas. Terminará sus estudios universitarios en Granada, licenciándose en 1859 tras haber conectado con la filosofía alemana (Kant, Hegel, Ahrens y Krause, principalmente) gracias a don Francisco Fernández y González, único profesor cuya cátedra salvaba del sentimiento de pérdida de tiempo que le quedó de sus años de estudiante en la ciudad andaluza. Quizá fueran esa inquietud y desasosiego los que le impulsaron a cultivar no solo sus estudios intelectuales sino también las artes, perfeccionando sus conocimientos musicales o su vocación hacia la pintura, llegando a tocar varios instrumentos - Mozart era su favoritoy a realizar varios retratos y escenas entre los que podemos destacar una cabeza de San Pablo o las ruinas de un templo griego que presidió durante muchos años el comedor de la ILE (Jiménez-Landi, 1996a: 85).

Entre las amistades forjadas durante estos años es inevitable resaltar la que estableció con Nicolás Salmerón, pues el destino imbricó sus nombres en las costuras de la historia en más de una ocasión. Tras su llegada a Madrid, en 1863, entabla amistad, entre otros, con el insigne Julián Sanz del Río, verdadero texto vivo para entender la evolución del pensamiento 
gineriano al amparo del krausismo. Allí trabajó como agregado diplomático y, al mismo tiempo, cursó el doctorado. Siempre le quedó tiempo para visitar el Ateneo, así como otros círculos culturales parecidos a los que ya frecuentaba en Granada y que le sirvieron para relacionarse con personalidades como, por ejemplo, Benito Pérez Galdós. En 1867, dos años después de alcanzar el grado de doctor en Derecho Civil y Canónico, y gracias a las influencias de su tío Antonio Ríos Rosas, que impidió el veto que hacia Giner se tenía por sus pensamientos krausistas, finalmente obtiene la cátedra de Filosofía del Derecho y Derecho Internacional de la Universidad Central. Ante él se abre un mundo de posibilidades que no tardará en volatilizarse cuando Julián Sanz del Río, Fernando de Castro y Nicolás Salmerón son apartados de sus cátedras por no aceptar las rígidas propuestas que el ministro Orovio trataba de imponer en cuestiones políticas y religiosas. Estamos ante el suceso conocido como la Primera Cuestión Universitaria. Giner protesta ante las destituciones de sus compañeros y amigos, sufriendo un destino similar.

Tras la revolución de 1868, los perjudicados no solo recuperan sus cargos sino también mayor poder para reformar la universidad que los desterró de sus cátedras. No obstante, el efímero Sexenio Revolucionario no fue suficiente para conseguirlo. Si la Septembrina repuso a los catedráticos, la Restauración borbónica devolvió el ministerio a Orovio, quien a través del Real Decreto de 26 de febrero de 1875 puso sobre la mesa, por segunda vez, la cuestión universitaria. Estado e Iglesia se enfrentaban de nuevo a la academia. Giner, entre otros, se negó a ceder el terreno conseguido y acatar nuevas normativas que seguían tratando de recortar la libertad y autonomía universitaria. La reacción por parte del Gobierno no se limitó a la separación de la cátedra, sino que recurrió también al destierro y a la prisión.

De esta forma volvería don Francisco a Cádiz: enfermo y afligido para ser encarcelado en el castillo de Santa Catalina, prisión militar. Allí se encargará de meditar y elaborar las bases de la ILE con el objetivo de fundar una universidad libre, completamente alejada de la que en esos momentos les repudiaba. En 1881 será repuesto en su cátedra y, simultaneando esfuerzos, continuará con su sueño de ver un nuevo florecer en España usando para ello la herramienta educativa. Alérgico a la vida pública que la política podía ofrecerle, «[n]o quiso ser subsecretario, ni ministro, ni siquiera caballero gran cruz de Alfonso XII, Orden creada para él. Fue Maestro — con M mayúscula—, maestro del pensar, el sentir y el querer» (Zozaya, 1915: 64). 
Sin entrar en más detalles sobre su vida, pues no es el objetivo de estas páginas, es ciertamente irónico pensar que una persona que se dedicó por completo a nutrir el espíritu de todos los que le rodeaban terminara muriendo, según su discípulo Cossío, de una gran desnutrición (JiménezLandi, 1996c). Evocando a su madre con su último aliento, don Francisco nos abandonó a primera hora del 18 de febrero de 1915, casi el mismo día que su respetado Pestalozzi. Al día siguiente, en su funeral, Giner ofreció su última lección: «quería enseñarnos a ser humildes y a ser inquebrantables enfrente de la muerte. Por ello prohibió, en la exposición y enterramiento de su cuerpo, toda pompa, todo ritualismo, todo aparato fúnebre que afeara o ridiculizara el trance augusto del no ser» (Dicenta, 1915: 43).

\section{Su institución}

D. Francisco Giner no tuvo hijos; no creó un hogar; es decir, lo creó, y muy grande. ¿Qué otra cosa que una inmensa familia era su Institución, alma de su alma, obra total suya, de aquel su enorme espiritu educador genial?

A. DE SEGOVIA

Admitimos que es ciertamente pretencioso encabezar este apartado con un posesivo que el mismo Giner rechazaría, pues no estuvo solo en esta empresa y, además, nunca quiso aparecer al frente, forzando con ello la elección de otra persona para el puesto que, por méritos, debía recaer en él (Castillejo, 1937). Incluso existen dudas sobre si la idea original fue suya, de Salmerón o quizá de ambos (Jiménez-Landi, 1996a: 334), pero lo cierto es que el «alma» de la Institución no fue otra que la de don Francisco:

En aquel grupo famoso de los discípulos de Sanz del Río, entre aquellos hombres animados todos del más sincero entusiasmo por la ciencia y la virtud, Azcárate, Calderón, Costa, Messía, Tapia, Salmerón, Soler, Quiroga, Caso, Linares, Cossío, Posada y tantos otros, fué [sic] D. Francisco siempre el fuego que encendía los corazones y el lazo que los conservaba unidos (García Morente \& De los Ríos, 1918: 60).

La historia no admite debate: «Francisco Giner de los Ríos y la Institución Libre de Enseñanza, o la Institución Libre de Enseñanza y Francisco Giner de los Ríos: dos nombres que aparecen siempre juntos y cuya separación es imposible» (Jiménez García, 1987: 131). Por ello creemos necesario hablar de su institución.

Así, convencidos de que para conseguir una nueva sociedad era preciso forjar un nuevo ideal de hombre, las bases y estatutos de la ILE son 
firmados el 10 de marzo de 1876. El 29 de octubre de ese mismo año, a las dos de la tarde, el presidente de la incipiente ILE, Laureano Figuerola, leía el discurso que abría el primer curso académico. El objetivo era fundar una universidad libre, a imagen de la que existía en Bruselas, pero pronto, gracias principalmente a los consejos de Azcárate y Figuerola (Jiménez-Landi, 1996a: 334), consiguieron el éxito centrándose en la segunda enseñanza, incluida desde sus comienzos, pero también con la enseñanza primaria. Del sueño de construir una educación superior de calidad, pasaron a alcanzar una calidad superior en los niveles educativos previos, entendidos de manera unificada. El interés que suscitó la iniciativa era tal que, viendo los nombres de sus valedores y accionistas, puede decirse que prácticamente «representaban a la España liberal en todas las esferas» (ibid.: 382).

Entre sus estatutos cabe destacar el artículo quince. El mismo que don Laureano Figuerola resaltó en el discurso de inauguración del primer curso académico y que el propio Giner usó en un breve escrito publicado póstumamente para conmemorar el cincuentenario de su obra:

La Institución Libre de Enseñanza es completamente ajena a todo espíritu o interés de comunión religiosa, escuela filosófica o partido político, proclamando tan solo el principio de la libertad e inviolabilidad de la ciencia y de la consiguiente independencia de su indagación y exposición respecto de cualquiera otra autoridad que la de la propia conciencia del profesor, único responsable de sus doctrinas (Giner, 1926: 20).

En este escenario, y rehusando siempre acudir al apoyo estatal para mantener la libertad a la que aspiraban, encontramos una institución educativa de paz, libertad de pensamiento, nuevas ideas y respeto mutuo (Castillejo, 1937). No había exámenes, ni libros de texto, y cada estudiante construía intuitivamente su propio material. Siempre que era posible, acudían a la fuente real de la enseñanza y no a su representación. La coeducación allí implantada era completamente novedosa y motivadora. Nada que ver, en definitiva, con los postulados memorísticos y librescos que solían atestar las aulas. Todavía hoy, algunos de estas propuestas serían novedad en nuestras aulas. Al concretar sus fuentes pedagógicas y su propia producción escrita, puede apreciarse que Rousseau, Pestalozzi y Froebel influyeron abiertamente en su obra (Molero, 2000: 76).

Alejado del estereotipo que todavía hoy se tiene hacia el maestro como persona de dudosa capacidad, la excelencia del profesorado fue un factor imprescindible para entender el éxito de Giner y sus correligionarios (Molero, 1987). El papel activo del alumno era esencial, pero siempre 
acompañado de maestros bien preparados. La figura del educador — diríamos hoy- es la principal variable del proceso educativo.

Paralelamente, recogiendo las ideas krausistas, la educación del cuerpo debía acompañar necesariamente a la instrucción de la mente, por lo que las excursiones y deportes eran comunes dentro de la ILE. La renovación pedagógica del siglo XX en España recogería con fuerza este testigo. Defendiendo una educación integral, a la par que neutra, tampoco se olvidaba el cultivo de las cualidades más humanas: «La inteligencia, por sí misma, da luz, no calor» repetía Giner a sus discípulos (1922: 132). Para los institucionistas la instrucción solo tiene razón de ser en cuanto puede cooperar a formar hombres en sentido universal, educador e íntimo (Giner, 1926: 25), buscando una realización total del ser humano que atienda y dé respuesta a la completa estructura que nos conforma. La educación integral que hoy jalona casi la totalidad de las leyes educativas era para - y en-Giner una realidad.

En un momento en que los maestros sufrían la desconsideración y el desprecio propios de un pueblo analfabeto, las conexiones de la ILE con las más punteras innovaciones pedagógicas del momento eran más que patentes. De esta forma, España estuvo abierta a las influencias extranjeras, extranjerizantes para un cierto sector que observaba estas conexiones con recelo (Martín-Sánchez Juliá et al., 1940). Entre otras, hay que destacar las influencias anglosajona, alemana, belga y francesa (Otero, 1994) y, con todo lo dicho, entenderíamos la simiente de históricos organismos y actividades que explican en gran medida la vida cultural de las primeras décadas del siglo pasado: Museo Pedagógico Nacional, Colonias Escolares, Misiones Pedagógicas, Junta para Ampliación de Estudios (JAE), Residencia de Estudiantes o Instituto-Escuela, por señalar los más relevantes. Intereses espurios aparte, nadie podrá nunca negar el éxito de la ILE como escuela, convento y hogar (Pijoán, 1927a). Todo ello nos lleva a preguntarnos: ¿cómo eran las clases de este austero y sobrio maestro?, ¿por qué es tan profunda la huella que Giner dejó en sus discípulos y compañeros?

Su cátedra

Su clase en la Universidad era la prolongación de sus amistades y familia. Ninguno de cuantos la visitaron podrá olvidar aquellos ratos en que sacudian el espiritu de penosas rutinas...

L. LÁZARO Y JUNQUERA

Al hablar de sus clases no nos referimos, fundamentalmente, a la metodología o al programa que llevaba a cabo, sino a la actitud que en ellas 
mostraba y al sentimiento que en ellas irradiaba. No queremos recoger vestigios de sus enseñanzas, sino de su educación. Antonio Zozaya recordó así su primer encuentro con «el gran Giner»:

Llegó hasta nosotros, nos saludó como a personas de su más alta estimación, nos tendió sus manos finas y nerviosas, calzadas de guantes amarillos, y nos invitó cortésmente a acompañarle al interior de la cátedra. No hay que decir que lo hicimos de muy buen grado y encantados de tan simpática acogida. Amigos míos —nos dijo, después de sentarse entre nosotros, como un camarada-, deseo hacerme merecedor del afecto de ustedes, y mi mayor pesar será no colaborar dignamente en la obra de cultura que «todos» juntos hemos de emprender. Yo no paso lista ni examino; así, la asistencia a mi clase es absolutamente voluntaria. Siento no ofrecer a ustedes mi libro de texto, porque no lo tengo, y lo dejo a elección de cada cual; en cuanto al programa, lo he impreso y suplico a ustedes que tengan la bondad de aceptarlo. Admitimos el ejemplar y no pudimos menos de pensar en la diferencia entre nuestro nuevo catedrático y otros que habían convertido la enseñanza en materia de explotación. Y comenzó un diálogo espontáneo, admirable, verdaderamente pedagógico. Comprendimos que estábamos en un universo nuevo [...] hasta entonces habíamos sido alumnos estudiosos; a partir de aquel día, comenzamos, en verdad, a ser hombres (Zozaya, 1915: 64).

Desde su cátedra, dentro del clima de complicidad arriba sugerido, Giner nunca desdeñó una idea de sus alumnos por absurda que fuera, estimulando a sus estudiantes a pensar y reflexionar a través del método socrático, despertando interés por la ciencia, respeto a la verdad y amor por la humanidad. El proselitismo no tenía cabida en sus lecciones, aceptando siempre la ideología e idiosincrasia de sus estudiantes.

La Filosofía del Derecho, materia que impartía, no era sino la excusa perfecta para ayudar a sus alumnos a crecer y madurar. Solía repetir la máxima de Kant: «Yo no enseño Filosofía, sino a filosofar [...] No enseñaba, pues, la ciencia, sino a pensar, y no pareciéndole aún bastante el saber pensar bien, hacía más: enseñaba a vivir» (García Morente \& De los Ríos, 1918: 62). Por este motivo no se preocupaba «de que sus discípulos conocieran una construcción filosófica o una teoría jurídica más, sino de que en el progresivo desenvolvimiento de su espíritu llegasen a un estudio más elevado y perfecto» (Ureña, 1915: 317).

Al no ser obligatorias para la obtención del grado, sus clases no solían estar abarrotadas; ni siquiera iban a diario todos los matriculados. Pese a ser un gran orador, Giner se cuidaba mucho de no hacer oratoria, cortando secamente sus palabras cuando el entusiasmo le llevaba a 
pronunciar un improvisado discurso para volver al tono familiar de la conversación, sencilla pero persuasiva, que le permitía charlar con la lengua y con el corazón. Cuando don Francisco se dejaba llevar por la situación, abandonándose a sí mismo hacia las cimas de la elocuencia, solía romper

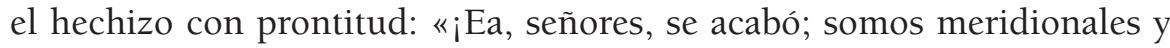
sensibleros, somos incorregibles!» (Palacios, 1926: 63); o "Cuidado, que estoy haciendo retórica» (Horrillo, 1931: 316). Incluso aquellos que no se sentían motivados por el contenido de sus clases reconocían la capacidad que tenía para atraer y remover el pensamiento de quienes lo escuchaban (Ballester-Soto, 1916). Unos estudian, otros escriben, pero su tragedia y función, como el mismo Giner reconoció, fue tener que hablar siempre con todo el mundo (Pijoán, 1927a), lo que él llamaba «el santo sacramento de la palabra» (Giner de los Ríos, 1965: 1). No obstante, de aquellas charlas y conversaciones salieron libros de extraordinario mérito (Horrillo, 1931). Así, de la palabra del educador, como semilla, obtuvimos excelentes frutos, algunos de ellos recogidos en las referencias de este artículo.

Además de no pasar lista ni realizar exámenes, raramente se sentaba o hablaba desde la plataforma: «Decía que su clase era como la plaza pública, libre para todo el mundo; pero no había clase de más orden, respeto, cortesía y educación, no impuestos por precepto, sino difundidos por el ejemplo que trascendía de la conducta y de los modos y maneras del profesor insigne y único [...] Y es que Giner, en todo procedía según pensaba» (Juncal, 1915: 72). Incapaz de mentir o de callar la verdad, era el ejemplo su mayor baza pedagógica, enseñando en sus paseos, conversaciones y tertulias de los miércoles tanto o más que en su cátedra o bajo el auspicio de la ILE: «¿Que antes de Giner de los Ríos hubo en España y en todas partes buenos maestros y excelentes profesores? Indudable. Pero Giner de los Ríos, sobre poseer las más altas virtudes, encarnó, personificó y enseñó como nadie la humanización de la enseñanza» («Estudiante y maestro», 1915: 1). Solo un educador con sólidas virtudes humanas es capaz de transmitirlas; la coherencia del educador, el alineamiento entre pensar y vivir son necesarios para educar.

En el antiguo decanato de la Facultad de Filosofía y Letras, un espacio pequeño, agradable y con cierta intimidad, a media tarde, en una suave luz y en discreto silencio, se reunía el maestro con sus discípulos. Las clases solían comenzar con la lectura del diario del curso, realizado y leído por los propios alumnos ante la supervisión y cuestionamiento de don Francisco: «Acostumbrado a ver deshechas, una por una, las afirmaciones que se había permitido hacer, el alumno adquiría pronto una cautela, 
una reserva, una prudencia peculiares, que constituyen uno de los estigmas más aparentes de los discípulos de D. Francisco Giner» (Bernaldo de Quirós, 1915: 187). Tras la lectura, daba comienzo una investigación, cimentada en el método socrático, y no era raro que la sesión terminara con una reflexión en voz alta por parte de Giner conforme moría la luz diurna y alguien, en respetuoso silencio, se levantaba para encender los candelabros que estaban sobre la chimenea que, en las tardes de invierno, revestía el aula de un resplandor tan cálido como el ambiente de enseñanza conseguido por don Francisco. Un recuerdo íntimo y melancólico, casi hogareño, que tiende (tendía) a repetirse:

El aula-laboratorio donde D. Francisco Giner de los Ríos daba su clase en la Universidad Central, en los años que yo la conocí — hace más de 30era como la palma de la mano, muy chiquitita, capaz para siete u ocho personas lo más. A la derecha, entrando, tenía una chimenea, pequeña también, que el bedel, Joaquín, un buen hombre, encendía los meses de invierno. De espaldas a esta chimenea, de pie, siempre de pie, cuántas veces, sin darse quizá cuenta, ha sido elocuentísimo, removedor, profundo. Era su sitio predilecto; de visión inolvidable (Horrillo, 1931: 315).

Amante de las cosas sencillas y desdeñoso de las superficiales e inertes, don Francisco pronto distinguía entre los estudiantes preocupados por el aprendizaje y los alumnos deseosos del éxito académico:

Cuando veía aparecer, en sus clases del Doctorado —él tenía una pupila de lince para conocer a las gentes- a esos estudiantones hueros que van a las aulas sin vocación alguna pero ávidos de obtener a fin de un año un papelito con una nota, para canjearlo más tarde por un diploma en papel vitela, sentía una profunda tristeza, una amargura que rara vez disimulaba. Llegaba hasta rogarles que se marchasen, que tomasen el programa $\mathrm{H}$ o el texto $\mathrm{B}$ para que, a fin de curso, el señor $\mathrm{X}$ los examinase (Machado, 1915: 220).

De esta forma, con la fina ironía cáustica que le caracterizaba, separaba el maestro el grano de la paja, el interés del interesado: «Viene usted con demasiados sobresalientes y demasiados premios — solía decir a los licenciados más sabihondos-; ya veremos si sirve usted para algo...» (Palacios, 1926: 62). Siendo consciente de que sus enseñanzas solo podían interesar realmente a unos pocos, «[a] consejaba con no fingida sinceridad que a la clase no viniesen sino los que tuvieren ese interés verdadero por la cosa. Y así, [... ] resultaba al cabo la clase reducida a un escaso número de verdaderos estudiosos, 8 o 10, entre los que siempre había algunos discípulos de 
años anteriores» (García Morente \& De los Ríos, 1918: 61). Era entonces, habiéndose quedado en intimidad, cuando empezaba realmente la clase. Sobre sus hombros pesaba con fuerza la responsabilidad de forjar seres humanos que construirían una España mejor. Como recuerda otro de sus discípulos, «[e]n un país donde todo está por hacer y es tan enorme el atraso, un hombre de la sensibilidad de D. Francisco no podía limitarse a sentarse en el sillón de profesor y lanzar diariamente una lección sin preocuparse del alumno» (Alas Argüelles, 1915: 254).

No importaba que estuviera dentro o fuera de un aula; Giner era educador allá donde estuviese, viviendo siempre por y para los demás: «y no solo dió [sic] doctrina y ciencia, que no era lo que él más estimaba, sino que dio [sic] vida e ideal y nobleza y ánimo y dignidad y profundo sentido del propio valor de la persona» (García Morente \& De los Ríos, 1918: 60-61). Al terminar las clases por cuestiones de horario, discípulos y maestro bajaban las escaleras juntos, siguiendo la clase oficiosa y ociosamente: «Recuerdo que un día nos dieron las siete en una farola de los bulevares. D. Francisco no tenía prisa cuando estaba comunicando a los jóvenes sus lecturas, sus estudios, sus enseñanzas» (Ballester-Soto, 1916: 287); estos llegaban incluso a seguirle en sus largos paseos a orillas del Manzanares para continuar recibiendo sus enseñanzas ( «La figura de actualidad», 1921). No importaba el lugar ni el momento; don Francisco no acudía a la cátedra, pues la cátedra siempre iba con él:

Y la cátedra no terminaba en la Universidad, ni en la Filosofía, ni - menos- en el Derecho: continuaba a la salida, en la calle, cuando acompañábamos al maestro; y seguía los domingos en el campo, o en la sierra, o en los pueblos aldeanos, embebiéndonos en la Naturaleza; o en los museos y las viejas ciudades castizas, reviviendo el Arte y la Historia, donde él nos descubría realmente a España, a la pasada y a la por venir —ila eterna!-, despertándonos en la verdadera adoración hacia ella... Que ya ni por casualidad se rozaba en la conversación el objeto limitado y concreto de la «clase», difundida y extendida entonces, en la comunión apasionada de las almas, a la vida afectiva y a la moral, y a la personalidad entera (Palacios, 1926: 63).

Todo educador que se precie conoce el valor del leitmotiv semper discentes. No era raro, por tanto, no solo ver compañeros y alumnos que volvían a sus clases por el mero gusto de disfrutar de sus enseñanzas, sino también encontrárselo, codo con codo, compartiendo asiento con otros estudiantes mucho más jóvenes que él. Así lo conoció Ballester-Soto, que vio a un viejecito nervioso entrar un poco tarde en la clase de Salmerón y, 
con extraordinaria atención, apuntar alguna frase o indicación de vez en vez, desapareciendo por la calle Ancha con agilidad tras terminar la clase (Ballester-Soto, 1916). Igualmente solía acudir a las clases de su querido Bartolomé Cossío, en el Museo Pedagógico (Jara, 1921). Incluso en sus propias clases don Francisco no dejaba de ser estudiante; en ellas no había catedrático, solo personas embriagadas por el espíritu investigador hasta conseguir un peculiar laboratorio de humanidad donde todos aprendían (Sánchez, 1918). De esta forma, es lógico comprobar cómo, en sus clases «no hacía lecciones seguidas, ni explicaba un sistema, ni siquiera un asunto monográfico determinado. Confiaba a los alumnos trabajos especiales, estos los producían en notas, sobre las que recaía el más minucioso estudio. El profesor suscitaba problemas, aportaba información, sugería dudas y reservas, provocaba nuevos estudios y confrontaciones, indicaba autores y libros y hablaba de su significación sobre los puntos más importantes (Palacios, 1926: 62).

Giner no era un hombre de masas; se sentía mejor en las distancias cortas y en grupos reducidos. En su cátedra, casi en familia, labró en tierra fértil. No obstante, pese a que sus clases fueron un oasis de educación en el desierto de la instrucción que por entonces predominaba, su mayor éxito extralimitó su cátedra, entendida esta como parte exclusiva del sistema educativo.

\section{Su huella}

¡Qué clase! Pero, ¿esta clase, hay que preguntar, esta clase única en su época, donde de modo tan admirable se enseñaba a trabajar y a pensar, era toda la labor del gran maestro para sus discípulos? Estoy por decir que ni siquiera la mejor; porque la clase, por ser clase, y aun dada por un maestro todo espíritu, saber, vocación, luz, pasión, es una cosa intelectual, y D. Francisco, por imperativo de su propia estructura y por amor a sus discípulos, atendía, para reformarlos, a todos los aspectos y direcciones de la vida, y no solo en la persona de sus discípulos. Por esto, D. Francisco donde era más grande, donde hacía más por las almas, donde más las conquistaba, era en su casita de la Institución, o en el campo, o en la calle.

A. HORRILlO

Sirvan las anteriores palabras para constatar la gran influencia que don Francisco tuvo no solo dentro sino también, y quizá sobre todo, fuera de la universidad. Educar es una profesión eminentemente vocacional; 
un maestro no trabaja enseñando, más bien vive enseñando sin llegar a distinguir con claridad la delgada línea que separa su trabajo del resto de facetas de la vida. Así era Giner, que alcanzaba su máxima expresión como educador cuando no se encontraba enseñando en su cátedra. Será, pues, dentro de los confines de su amada ILE, así como en las numerosas excursiones y conversaciones informales que de ella surgieron, donde realmente encontremos los orígenes de la profunda huella que dejó en los que le conocieron: tanto adultos como niños.

Como hemos comentado anteriormente, la ILE surgió con la intención de llegar a ser una universidad libre, con ciertos tintes ateneístas (JiménezLandi, 1996b), pero pronto cambió de rumbo al conservar la educación secundaria y al poco tiempo instaurar la primaria (1878) e incluso una escuela de párvulos (1885). Este giro no solo tuvo como causa la falta de medios para sostener tamaña empresa, sino también la intuición de que el verdadero cambio que habría de dar una España mejor, para llegar a tener profundas raíces, debía ser sembrado cuanto antes. Giner así lo reconoce al citar a San Anselmo: «Si plantáis un árbol, y lo atáis y apretáis por todas partes, de suerte que no pueda extender sus ramas, ¿qué os encontraréis, cuando lo desatéis, al cabo de muchos años? Un árbol con las ramas torcidas y encogidas» (Giner de los Ríos, 1910: 290). El cambio universitario no solo era difícil de conseguir, sino quizá también demasiado tardío de ser alcanzado. Era preciso influir prontamente en la juventud. Desde este nuevo prisma, y precisamente por haber sido un gran pedagogo, don Francisco nunca fue pedante. La magia que ofrecía a sus estudiantes universitarios no desaparecía al relacionarse con la infancia; las clases que Giner impartía en la ILE, al igual que las de su cátedra, estaban llenas de vida y aprendizaje socrático en estado puro:

Si en el trato con jóvenes y hombres poseía ese tacto, ese delicado sentimiento de adaptación, en el trato con los niños, era admirable el arte con que sabía compenetrarse en seguida con las frágiles y vacilantes emociones de la tierna edad. Nunca fingía la puerilidad; nunca jugaba a niño; nunca hacía ese ademán de condescendencia, como quien se rebaja a tratar con párvulos. [...] iqué sensación tan profunda entre de admiración y ternura hemos sentido al verle y oírle en alguna de sus clases con los niños de la Institución Libre de Enseñanza! Los chicos hablaban, interrumpían, se interrogaban unos a otros y al maestro. Jamás aquello fué [sic] desorden ni algarabía, sino el movimiento natural de un interés que Don Francisco ingenuamente despertaba a cada cosa que decía. En apariencia, allí se charlaba; en realidad, se pensaba, y a los pocos minutos de oir [sic] aquella clase, veíase cómo las cuestiones iban de suyo 
suscitándose unas a otras en la discusión ordenada de los infantiles ingenios. D. Francisco, de vez en cuando, con una observación, con una objeción situada en el plano mismo en que se movía el discurso, reponía las cosas en su punto o alzaba como por encanto un tramo más el nivel de la conversación. Hemos oído a chicos de 12 años discurrir sobre Metafísica con ingenua, sí, pero certera agudeza. Hemos visto a Don Francisco enseñar historia de las religiones en unas clases en donde el que menos hablaba era el maestro mismo (García Morente \& De los Ríos, 1918: 62).

Con todo, observamos cómo en los jardines y aulas de la Institución Giner fue un excelente guía de la juventud (Mesa, 1920). Allí, junto a aquellos espíritus vírgenes, don Francisco se convertía en el abuelito, normalmente rodeado de racimos de chiquillos, entre los árboles del jardín (Pijoán, 1927a). El recuerdo que dejó en los corazones de los niños es entrañable:

Los párvulos aguardábamos, jugando en el jardín de la Institución, al maestro querido. Cuando aparecía D. Francisco, corríamos a él con infantil algazara y lo llevábamos en volandas hasta la puerta de la clase [...] En su clase de párvulos, como en su cátedra universitaria, D. Francisco se sentaba siempre entre sus alumnos y trabajaba con ellos familiar y amorosamente [...] Toda la España viva, joven y fecunda acabó por agruparse en torno al imán invisible de aquel alma tan fuerte y tan pura (Machado, 1915: 220).

En realidad, entendía Giner que debía haber continuidad entre las tres etapas del sistema educativo: «La universidad tendría, [...] a la vez que carácter profesional, carácter general, constituyendo en este último respecto un nuevo grado del mismo tipo que la escuela primaria y la secundaria, y en continuidad indivisa con esta» (Giner, s/f).

No es por tanto de extrañar que, gracias a su cercanía y carisma, bien desde la cátedra o desde la ILE, se llegara a afirmar que fue el hombre del momento que más influyó en España, dando muchos de los profesores y políticos, entre otros profesionales, más eminentes que ha visto nuestro país. Y que incluso tuvo — quizá con cierta exageración pero significativamente comparado- «más influencia social en ciertos aspectos que todas las órdenes religiosas juntas» (Juncal, 1915: 72). La profundidad de la huella que dejó es de tal magnitud que quedó escrito:

Si algún día España llega a ser grande en el mejor sentido de la palabra y los pueblos civilizados del planeta vuelven hacia nosotros su mirada, acaso haya historiadores superficiales que escriban cuatro palabras sobre el maestro, sin concederle apenas importancia. Pero si algún historiador de espíritu se ocupa entonces de contar los orígenes de nuestro 
engrandecimiento, buscándolo en sus causas remotas, llegará después de seguir mil caminos subterráneos, a colocar en puesto culminante al viejecito modesto, bueno y pulcro que ahora descansa provisionalmente en el cementerio civil entre sus amigos y maestros (Alas Argüelles, 1915: 255).

Cierto día, uno de sus estudiantes se lamentaba de que por no haber salido nunca de España, solo había conocido a don Francisco. Otro de sus discípulos le contestó sin dudarlo: «Ni aunque hubieses visto Universidad por Universidad y Seminario por Seminario de toda Europa, encuentras otro D. Francisco. Profesores eminentes, sí, muchos; pero un maestro, un maestro como D. Francisco, en ninguna parte» (Horrillo, 1931: 316). Altamira, en este sentido, afirmó que había que remontarse a Jovellanos para encontrar semejanzas morales e intelectuales suficientemente elevadas como para asemejarlas a las de don Francisco (1915a: 59).

Sabio, generoso, bueno, recto, amable, inteligente, dulce, tolerante, finamente irónico, austero, sencillo, afable, modesto, curioso, sociable, gracioso, enérgico, virtuoso, elocuente, seductor, poético, inolvidable... Los adjetivos que resaltan los porqués de su magnética personalidad educadora son tan numerosos como múltiples son los discípulos que le honraron con sus recuerdos. Según parece, uno de los últimos libros que don Francisco tuvo el placer de disfrutar fue Platero y yo. Una obra íntima, tierna, sencilla, exquisita y única, según un escrito de Giner al autor (Jiménez-Landi, 1996c: 84). Por su parte, así lo recordó Juan Ramón Jiménez:

Iba y venía, como un fuego con viento; y se erguía, silbante víbora de luz; y se derramaba y se prendía, chispeante enredadera de ascuas; y se abalanzaba, leonzuelo relampagueante; y se encauzaba, reguero puro de oro; y aparecía, sin unión visible, aquí y allá, por todas partes, delgado, aéreo, inasequible, con la elasticidad libre de la diabólica llama [...] Sí, una alegre llama condenada a la tierra [...] más que nada, luz, graciosa luz, luz (Jiménez, 1924: 224).

Luminosidad que, lejos de apagarse, quedó albergada en el alma de sus discípulos. Se atribuye a Horace Mann la autoría de esta sentencia: «El maestro que intenta enseñar sin inspirar en el alumno el deseo de aprender está tratando de forjar un hierro frío»; nada que ver con la luz que Giner irradiaba, siempre llevada a la realidad de los actos. La influencia de un maestro convierte la docencia en un ejercicio tan duradero como profundas y sentidas sean sus enseñanzas. No es una locura pensar que don Francisco, a través de estos cien años, de corazón en corazón y mientras sea recordado, sigue de algún modo entre nosotros. 


\section{Conclusiones}

Don Francisco Giner ha constituido un caso excepcional en la historia de la España contemporánea. Pudo serlo todo, llegar a todo, alcanzar las más útiles posiciones, las más ventajosas prebendas, y renunció, no solo a lo honorífico, sino a lo positivo y práctico. No necesitaba nada, porque su exclusivo anhelo era hacer aquella fecunda siembra de ideas y de estímulos, y lo que vale más aún, de amor y de cordialidad.

E. MESA

En el centenario de su muerte, el recuerdo de Francisco Giner de los Ríos evoca la imagen de un maestro generoso, amable y cercano, capaz de infundir respeto (auctoritas) sin necesidad de imponerlo (potestas), encendiendo el amor, avivando el entusiasmo y moderando la pasión (García Morente \& De los Ríos, 1918).

La coherencia entre sus ideales y acciones le granjeó el reconocimiento de los que en él vieron fuente de luz, constancia y bondad. Para él, como para cualquier moralista, lo esencial era la conducta y no solo la luz que otorga el saber (Altamira, 1915a: 60). Fue maestro dentro y fuera del aula, respetando al alumno bajo un principio de humanidad sabiamente atemperado que le hizo sobrepasar las categorías establecidas hasta llegar a la más alta cota educativa: «Más aún que pensador y jurista, fué [sic] Don Francisco Giner educador, foco ardiente de vida y doctrina, cuyos rayos penetraban hasta en lo más íntimo de quienes se movían en torno suyo. Nadie de los que le conocieron y trataron escapó a su poderoso influjo» (García Morente \& De los Ríos, 1918: 60).

Observando sus hábitos, es inevitable preguntarse cuántos profesores de universidad, hoy en día, suelen acudir a las clases de sus compañeros para escucharles, tomar notas y aprender de ellos. Sin duda habrá quien considere que el avance de las TIC hace innecesario acudir físicamente al aula del compañero, perdiendo con estas erróneas justificaciones el aspecto humano que debería prevalecer en toda educación superior. Mientras que los libros y artículos que llegan a nosotros están cargados de saber, la sabiduría es más difícil de plasmar en papel. Esencia que otro grande de nuestro campo, Ortega y Gasset, supo apreciar al acuñar su «Pedagogía de la contaminación» (1982), recordándonos que solo a través del contacto físico podremos superar la visión mecánica de la enseñanza. ¿Dónde quedó la humanidad que hacía de la universidad un conjunto, una pluralidad, pero no solo de saberes sino de personas? (Giner de los Ríos, 1910: 
306). ¿No sería preciso, pues, dirigir nuestros pasos hacia una universidad más humana? (González Geraldo, 2014).

Antítesis de dómine, sus estudiantes paladeaban cada momento sin importar la hora de finalización de las clases. Niños y no tan niños, todos por igual como igual era la dedicación y compromiso que a todos profesaba. Actualmente, la motivación del alumnado sigue siendo una de las preocupaciones que los docentes no acaban de resolver; con frecuencia, los estudiantes están más pendientes del reloj que de las lecciones, huyendo en tropel al segundo siguiente de la hora límite. El amor incondicional que hacia ellos tenía Giner residía en el deseo de convertirlos en seres humanos «aptos para la lucha científica y social, que pudieran, con el natural desarrollo e incontrastable empuje de una rica y exuberante actividad, dar días de gloria para la patria [...] ¡Quién podrá sustituir a tan inolvidable maestro!» (Ureña, 1915: 317).

Sin duda, como ya hemos apreciado, Giner pudo tenerlo todo, pero prefirió labrar en la árida pero hermosa tierra de la juventud española, renunciando a su gloria personal en favor de la colectiva (Reyes, 1925). No hay mayor sacrificio para quien desee considerarse educador. Era un caso de abnegación viviente; no ambicionaba fortuna ni gloria, dinero ni vanidad. Quería solo ser útil a la humanidad, derrochando lo único que poseía: el tesoro inagotable de su ciencia (Ballester-Soto, 1916). Era amante de la ciencia, la justicia, la libertad y, ante todo, del ser humano. Siempre con gente joven, don Francisco amaba profundamente la juventud y lo que ella significaba como deseo de porvenir:

...mi protector comenzó a hablarme de la Patria, del porvenir de España, de la miseria de los campos, de la misión de sus juventudes — de la altísima misión de las juventudes españolas-, del abandono cultural... [...] El viejecito misterioso tenía una receta, una receta tan misteriosa como él, con la que fabricaba juventud (Martín Granizo, 1916: 159).

Quede en nuestros corazones la obra lenta, pero segura, de don Francisco, que no era otra que la siembra de humanidad, pues nada de lo humano le era ajeno (Pijoán, 1927b). Desde allí, en lo más hondo de nuestra vocación por la docencia, «entre el deseo de honrar su memoria y el temor de profanarla» (Zulueta, 1915: 45), y a sabiendas de que la obra principal de don Francisco fue hecha y disfrutada por los que en vida lo conocieron, intentaremos pagar la eterna deuda de gratitud que, como educadores, sin duda, tenemos con él: 
A algo más que querer y a llorarle está usted obligado. Cumpla usted con su deber. [...] Lleve usted a D. Francisco a la escuela para que sus discípulos le conozcan y le quieran como le conoce y quiere usted. Les hará usted un gran bien. Vivo, fué [sic] D. Francisco un gran maestro. De nosotros depende que lo siga siendo aun después de muerto (Llorca, 1915: 255-256).

\section{Bibliografía citada}

Alas ArgüELLES, L., «Nuestro don Francisco», BILE [Boletín de la Institución Libre de Enseñanza], 665 (1915), pp. 254-255.

Altamira, R., «Giner de los Ríos», BILE, 659-660 (1915a), pp. 59-62.

- Giner de los Ríos. Educador, Valencia, Prometeo, 1915b.

BAllester-Soto, V., «El Maestro de Maestros que se fue. Don Francisco Giner de los Ríos», BILE, 678 (1916), p. 287.

Bernaldo De Quirós, C., «La clase de D. Francisco», BILE, 663 (1915), pp. 186-188.

Castillejo, J., Wars of ideas in Spain. Philosophy, Politics and Education, London, John Murray, 1937.

DiCENTA, J., «La última lección», BILE, 659-660 (1915), pp. 43-44.

«El aniversario de D. Francisco Giner de los Ríos», El Día. Diario de la Noche, 18 de febrero de 1917, p. 1.

«Estudiante y maestro», El País, 19 de febrero de 1915, pp. 1-2.

García Morente, M. \& F. DE los Ríos, «El Pedagogo», BILE, 695 (1918), pp. 60-63.

García Velasco, J., Francisco Giner de los Ríos. Un andaluz de fuego, León, Fundación Sierra Pambley, 2011.

GINER DE LOS Ríos, F., Pedagogía universitaria, Barcelona, Manuales Soler, c. 1910.

- BILE, 714 (1919), pp. 287-288.

- Obras completas, VII: Estudios sobre educación, Madrid, La Lectura, 1922.

- En el cincuentenario de la Institución Libre de Enseñanza, Madrid, Olózaga, 1926.

- Ensayos y cartas. Edición homenaje en el cincuentenario de su muerte, México, Tezontle, 1965.

GONZÁlez GERAldo, J. L., «Nuevos tiempos, viejas ideas: la influencia de la ILE en los roles de maestros y estudiantes de escuela del siglo XXI», CITE 2011. XII Congreso Internacional de Teoría de la Educación, 2011, pp. 1-20.

- Hacia una universidad más humana. ¿Es superior la educación superior?, Madrid, Biblioteca Nueva, 2014.

Horrillo, A., «La clase de D. Francisco Giner», BILE, 858 (1931), pp. 315-316. 
Jara Urbano, A., «Un día triste», BILE, 734 (1921), pp. 158-159.

JimÉnEZ GARCíA, A., El krausismo y la Institución Libre de Enseñanza, Madrid, Cincel, 1987.

JiMÉNEZ LANDI, A., La Institución Libre de Enseñanza y su ambiente. Los orígenes de la Institución, I, Madrid, Ministerio de Educación y Cultura, 1996a.

- La Institución Libre de Enseñanza y su ambiente. Los orígenes de la Institución, II, Madrid, Ministerio de Educación y Cultura, 1996b.

- La Institución Libre de Enseñanza y su ambiente. Los orígenes de la Institución, IV, Madrid, Ministerio de Educación y Cultura, 1996c.

JimÉnEz MANTECón, J. R. [Juan Ramón Jiménez], «Elegía a la muerte de un hombre», BILE, 782 (1924), p. 224.

JUNCAL, J., «El maestro y su obra», BILE, 659-660 (1915), pp. 70-72.

«La figura de actualidad», BILE, 740 (1921), pp. 351-352.

LÁzAro y Junquera, L., «Don Francisco Giner de los Ríos», BILE, 666 (1915), pp. 287-288.

LlorCA, A., «Don Francisco Giner de los Ríos», BILE, 665 (1915), pp. 255-256.

LÓPEZ-MORILlas, J., «El arte de hacer hombres» [conferencia], Fundación

Juan March, 1989; <http://www.march.es/conferencias/anteriores/voz.aspx? pl=21890\&l=2> [consulta: 30 abril 2015].

Machado, A., «D. Francisco Giner de los Ríos», BILE, 664 (1915), pp. 220-221.

MARTín GRANizO, L., «El genio de la pedagogía», BILE, 674 (1916), pp. 158-159.

MARTíN-SÁNCHEZ JULIÁ, F. et al., Una poderosa fuerza secreta. La Institución Libre de

Enseñanza, San Sebastián, Editorial Española, 1940.

MESA, E., «Giner», BILE, 721 (1920), p. 127.

Molero PintAdo, A., «El modelo del maestro en el pensamiento de la Institución Libre de Enseñanza», Revista Interuniversitaria de Formación del Profesorado, 0 (1987), pp. 7-22.

- La Institución Libre de Enseñanza: un proyecto de reforma pedagógica, Madrid, Biblioteca Nueva, 2000.

ORTEGA Y GASSET, J. [1930], Misión de la Universidad y otros ensayos de educación y pedagogía, Madrid, Alianza, 1982.

Otero UrtazA, E., Manuel Bartolomé Cossío. Trayectoria vital de un educador, Madrid, Amigos de la Residencia de Estudiantes / CSIC, 1994.

PAlAcios, L., «La Cátedra de Giner», BILE, 791 (1926), pp. 59-63.

PijoÁn, J., «Mi Don Francisco Giner (1906-1910)», BILE, 813 (1927a), pp. 383-384.

- Mi Don Francisco Giner (1906-1910), San José de Costa Rica, Repertorio Americano, $1927 \mathrm{~b}$.

Programa de la Institución Libre de Enseñanza. Primer Centenario 1876-1976. Madrid, Revista de Occidente, 1976. 
REYES, A., «Don Francisco Giner de los Ríos. Hoy se cumple el X aniversario de su fallecimiento», BILE, 783 (1925), pp. 181-182.

SÁNCHEZ, B., «El maestro de los maestros», BILE, 700 (1918), pp. 209-211.

SEgOviA, A. de, «D. Francisco ha muerto», BILE, 659-660 (1915), pp. 81-82.

UREÑA, R., «El Catedrático», BILE, 667 (1915), p. 317.

ZozAYA, A., «Don Francisco el Magno», BILE, 659-660 (1915), p. 64.

ZuluetA, L., «Don Francisco», BILE, 659-660 (1915), pp. 45-48.

Fecha de recepción: 30-4-2015

Fecha de aceptación: 3-10-2015 